\title{
Interações entre Defesa e Inteligência: a Contribuição desses Setores para a Realização de Interesses Nacionais
}

\section{Interactions between Defense and Intelligence: the Contribution from these Sectors to the Achievement of National Goals}

FÁBIO NOGUEIRA MIRANDA FILHO

\section{INTRODUÇÃO}

Segundo a Organização das Nações Unidas (ONU), Segurança é definida como condição na qual os Estados consideram que não há perigo de ataque militar, pressão política e coerção econômica, de modo que possam, livremente, buscar o seu próprio desenvolvimento e progresso (Brasil 2005). Ou seja, os Estados que gozam de Segurança têm a oportunidade, a partir de um ambiente mais estável, de evoluir internamente, além de poder ocupar posição mais elevada na ordem internacional. Por corolário, a Segurança Nacional, tomando por base o Estado Democrático de Direito, exige também poder militar convincente e sério a fim de auxiliar na manutenção da ordem interna, bem como respaldar e estimular soluções diplomaticamente negociadas com outras nações para, desse modo, contribuir na realização dos interesses nacionais.

Por conseguinte, para equipar de forma adequada as Forças Armadas, um dos principais responsáveis pela Segurança Nacional, é necessário, entre outras atitudes, desenvolver a Indústria de Defesa. Como consequência primária do desenvolvimento dessa Indústria, o Brasil desenvolveria tecnologia nacional e dependeria menos de importações, principalmente em setores passíveis de restrição de acesso como bens e tecnologias de uso dual, isto é, aqueles que podem ser usados tanto em projetos civis como militares. Por exemplo, o lançamento de satélites do Sistema Geoestacionário Brasileiro (SGB), que vai atender ao Plano Nacional de Banda Larga

Fábio Nogueira Miranda Filho - Mestre-profissional em Administração de Empresas (PUC-Minas), Oficial de Inteligência da Agência Brasileira de Inteligência (ABIN). E-mail: fabionmf@hotmail.com. 
(PNBL) - uso civil -, e servir às comunicações estratégicas das Forças Armadas brasileiras - uso militar.

Para tanto, vários setores da sociedade, como academia, órgãos governamentais, diplomacia, etc., podem contribuir, alguns mais outros menos, para a garantia da Segurança e desenvolvimento do setor de Defesa. Contudo, os órgãos que executam Inteligência estratégica podem assessorar a execução desta diretriz de maneira diferenciada, pois apresentam inúmeras sinergias com o campo da Defesa, a exemplo de seus objetivos que se entrelaçam. Ambas visam à garantia da Segurança econômica e institucional dos países a que pertencem. Estas atividades são correlatas, tanto em tempos de paz, ao estarem atentas às situações potencialmente prejudiciais aos interesses da sociedade, como em tempos de guerra, em que a Inteligência permite ao Estado mobilizar esforços de acordo com a intenção do inimigo.

Defesa e Inteligência também se ressentem de algumas objeções em comum, como por exemplo, obter recursos financeiros para seu próprio desenvolvimento, e angariar reconhecimento da sociedade por aquilo que são efetivamente incumbidas de fazer: as Forças Armadas são normalmente lembradas por outros atributos (segurança pública, auxílio em defesa civil, etc.) que não a Defesa nacional; já a Inteligência é mais exposta quando falha e não quando antecipa situações prejudiciais ao país.

Tendo em vista o apresentado até o momento, este artigo pretende mostrar, com destaque para o contexto brasileiro, qual o caminho para desenvolver o setor de Defesa que seja mais profícuo para a sociedade e, além disso, evidenciar a contribuição do processo de interação da Inteligência com a Defesa para promover a Segurança Nacional e o desenvolvimento do país. Para além dessa introdução, é apresentada a metodologia de trabalho, e nas seções seguintes, são analisados tópicos da relação entre Inteligência e Defesa, culminando com as considerações finais em que são apresentadas as implicações a estes setores, bem como sugestões de temas a complementar a pesquisa.

\section{TÓPICOS E NÍVEIS DE ANÁLISE}

Na construção desse artigo, procura-se aproximar, no âmbito brasileiro, os setores da Defesa e Inteligência, fazendo um questionamento reconstrutivo do campo de estudos - afinal, o debate visa antes abrir perspectivas do que chegar a resultados definitivos (Demo 2013). Dito de outra forma, a preocupação metodológica conduz ao esforço de analisar de modo qualitativo em cinco tópicos com níveis de abrangência diferentes o fenômeno das interações entre esses setores e quais seriam as melhores escolhas para o 
desenvolvimento do setor de Defesa, do ponto de vista da contribuição para o alcance da Segurança Nacional e, por conseguinte, ambiente propício ao desenvolvimento do país.

A escolha destes tópicos não precisa e não deve ser realizada de forma aleatória, já que o objetivo é a compreensão ampla do fenômeno, e não sua representatividade estatística (Einsenhardt 1989). Assim, para traduzir a expressão "mais profícuo para a sociedade", utilizada na introdução para definir o melhor caminho de desenvolvimento do setor de Defesa, adotam-se, de forma basilar, os parâmetros de maior utilidade para a sociedade brasileira e probabilidade de realização, em outras palavras, se as ações empreendidas pelo setor da Defesa, em cada tópico, se revelam proveitosas para o conjunto da sociedade e possuem boa chance de se concretizarem. Quanto ao exercício da Inteligência, ponderando a Defesa como tema central, ela é aqui apresentada como uma atividade de apoio, que contribui de forma diferenciada para o desenvolvimento deste setor. Ainda sobre a Inteligência são apontadas algumas precauções para que este auxílio à Defesa seja realmente eficaz.

Dessa forma, tendo em vista o nível de análise mais abrangente, a escolha do primeiro tópico tem como critério técnico as prioridades do Estado brasileiro, pelo menos as mais consensuais a serem discutidas adiante - tópico "Segurança Nacional". O segundo critério, em um nível mais restrito de análise, são as prioridades do sistema de Defesa nacional, explicitadas em seus documentos de mais alto nível, a Política Nacional de Defesa (PND) e a Estratégia Nacional de Defesa (END) - tópicos "Política e Estratégia de Defesa" e "Política pública de desenvolvimento da Indústria de Defesa” (Brasil 2005, 2008). Nos níveis de análise mais específicos, há um desdobramento de ações e exemplos do que seria pertinente no desenvolvimento do Setor de Defesa, considerando as prioridades estabelecidas nas análises anteriores - tópicos "Bens e tecnologias de uso dual" e "Casos concretos de acesso e restrição a bens e tecnologias de uso dual".

Com base nesses critérios, por meio de exame transversal das atuações do sistema de Defesa Nacional e do Serviço de Inteligência (SI), foram elencados esses cinco tópicos de análise. Cada tópico pertence a um nível de abrangência diferente, do mais amplo e político ao mais específico e concreto, conforme ilustra a Figura 1. Por fim, nas Conclusões, a partir das evidências discutidas nas seções seguintes, é apresentado modelo que relaciona Indústria de Defesa, Inteligência, Segurança e interesses nacionais. 


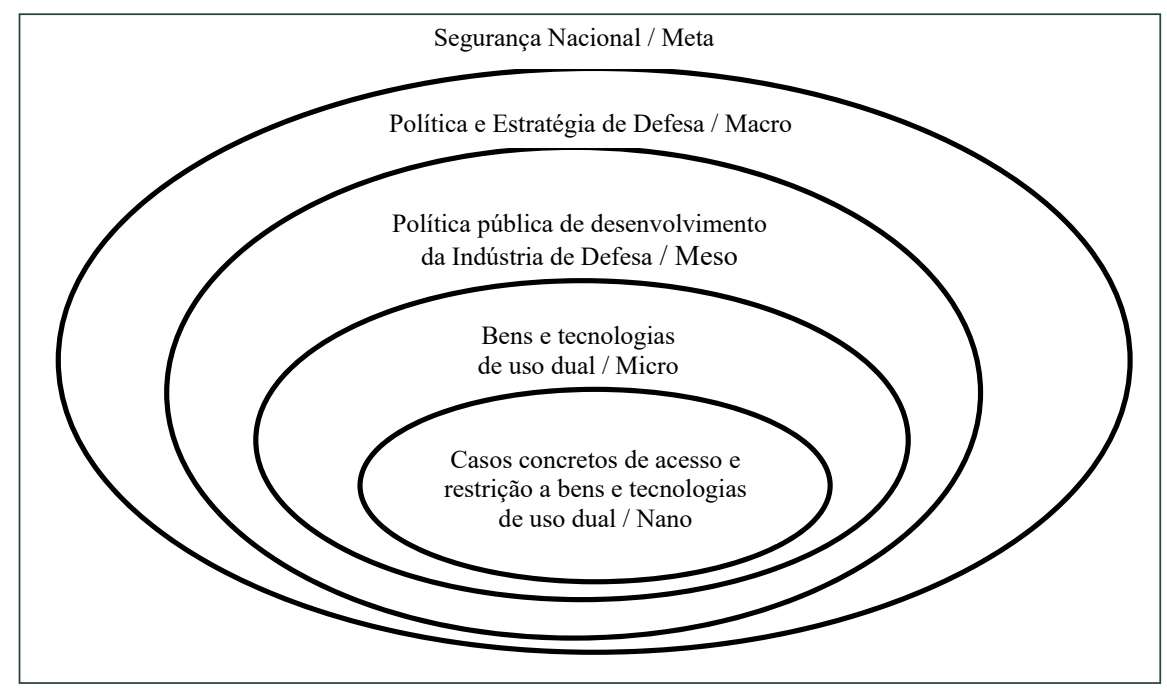

Figura 1 - Tópicos e níveis de análise

Fonte: Elaborado pelo autor.

\section{SEGURANÇA NACIONAL - NÍVEL META}

De modo semelhante à $\mathrm{ONU}$, a PND, que rege a atuação das forças armadas do Brasil, define Segurança como "a condição que permite ao país a preservação da soberania e da integridade territorial, a realização dos seus interesses nacionais, livre de pressões e ameaças de qualquer natureza, e a garantia aos cidadãos do exercício dos direitos e deveres constitucionais". Todos os elementos deste conceito são facilmente apreendidos após consultas a livros, dicionários e enciclopédias, exceto interesses nacionais. Da mesma forma, a constituição do Brasil de 1988 apresenta os objetivos do país no artigo $3^{\circ}$, porém ainda sem elucidar de forma cabal o termo interesse nacional, a exemplo do segundo item desse artigo, "garantir o desenvolvimento nacional".

Sem dúvida, arrolar o que compõe o interesse nacional varia no tempo e de país a país, oscilando também conforme extrato social da população, seja por faixa etária, nível de renda ou qualquer outro critério. Além disso, a liberdade de pensamento dos cidadãos, sobretudo em democracias, leva a incontáveis listagens de interesses nacionais, às vezes até contraditórios. Recordando Hobbes, o interesse individual é balizado por custo e benefício, porém é disciplinado pelo medo da anarquia, o que leva os homens a respeitar as leis e a se tornarem mais previsíveis, aceitando o Estado como 
protetor (Hobbes 1985). Contudo, o interesse nacional não é passível de ser guiado pelo mesmo artifício, pois não há uma governança supraestatal, como um Estado protetor de todos os outros Estados.

Ainda assim, o interesse nacional, com matiz político e cunho predominantemente econômico-social, apresenta alguns consensos em sua parte mais abstrata, que pode ser chamada de núcleo duro, tais como prosperidade, independência e justiça social, restando sua maior divergência na forma de como conduzir o país para atingir tais fins (Ribeiro 2008). Para ilustrar a realização dos interesses nacionais citam-se os "Anos Dourados", entre as décadas de 50 e 70 do século passado, em que vários governos do mundo ocidental tiveram "liberdade para seguir os objetivos gerais de políticas sobre as quais não havia grandes desacordos" (Hobsbawn 2003). Não se pode esquecer que as crises costumam solapar o consenso político.

A partir deste consenso em torno do núcleo duro, com o patrocínio da Segurança, governos, empresas e cidadãos procuram realizar o interesse nacional interna e externamente. No campo doméstico, no caso brasileiro o interesse nacional seria, de forma sucinta, construir sociedades livres e pacíficas, erradicar a fome e a pobreza, promover crescimento econômico sustentável e inclusivo, prover educação e revitalizar a parceria global (Brasil 1988; ONU 2015). Já no campo externo, levando em conta que os Estados são atores interessados em si mesmos, seria projetar os interesses nacionais no cenário internacional, se resguardando de interferências externas (Waltz 1979).

Nessa busca pela estabilidade do Estado e prevenção contra os acasos da deusa Fortuna (Maquiavel 1979), os governos recorrem regularmente aos seus SIs, uma vez que se destacam entre as funções do SI antecipar situações relevantes ao país, sinalizar oportunidades e proteger informações com fins a garantir a Segurança do Estado (Diniz 2002; Proença Junior 2009). Em tempo, por Inteligência entende-se a informação coletada e processada pelo SI para assessorar tomadores de decisão (Bimfort 1958; Cepik 2002; Moore 2007). No Brasil, as ações de planejamento e execução das atividades de Inteligência do país ficam a cargo da Agência Brasileira de Inteligência (Abin), órgão central do Sistema Brasileiro de Inteligência (Sisbin), composto por 35 órgãos de 18 ministérios e órgãos da Presidência da República (Brasil 1999).

Tomando emprestados conceitos da teoria econômica de Custos de Transação (Williamson 1975, 1985), o SI trabalha no sentido de diminuir custos pertinentes às negociações do Estado, tendo em vista a racionalidade limitada e a incerteza dos tomadores de decisão, e também do custo do oportunismo de agentes externos que podem usufruir de assimetria de informação. Entretanto, cumpre destacar que os produtos da Inteligência 
são apenas um dos fluxos informacionais que influenciam o processo de tomada de decisão, além de não poderem ser acusados por boa ou má decisão (Cepik 2002; Odom 2008).

Por exemplo, logo após os atentados de 11 de setembro, em comissões do congresso americano, foi dito que funcionários de SIs americanos afirmaram que o Irã não tinha bomba nuclear e nem conseguiria fazê-lo em curto espaço de tempo, o que acabou definindo a não intervenção dos Estados Unidos. Contudo, este fato, por si só, não poderia determinar a decisão de instâncias superiores do governo americano se haveria guerra ou não entre os dois países (Odom 2008). Outrossim, durante a Segunda Guerra Mundial, foi constatado que generais americanos de melhor desempenho foram aqueles ávidos pelas informações da Inteligência e abertos a quaisquer análises, mesmo recebendo julgamentos desfavoráveis e contrários à visão deles sobre a guerra (Deutsch 1988).

\section{POLÍTICA E ESTRATÉGIA DE DEFESA - NÍVEL MACRO}

Segurança é vista como estado, e Defesa, ação para alcançar e manter este estado (Silveira 2004; Proença Junior 1998). A Segurança apresenta duas vertentes: interna, associada à segurança pública e utilização de força em seu próprio território; e externa, relacionada à Defesa da nação perante questões exteriores. Em ambos os casos, é apropriado afirmar que é necessário ter forças de coerção e dissuasão bem preparadas, porém com maior ênfase para polícias e poder judiciário no caso interno e forças armadas para o externo, nestas circunstâncias sem detrimento da importância da diplomacia.

Devido à vocação maior das Forças Armadas, a PND está voltada para manter a Segurança em relação às ameaças internacionais, como conflitos de caráter étnico e religioso, disputas por áreas marítimas e fontes de água doce, instabilidade econômica, tecnologia mais avançada em outros países, etc. Após confecção do PND, para efetividade de ação em busca do estado de Segurança, foi concebida a END lastreada em três eixos estruturantes: reorganização das Forças Armadas para melhor desempenhar suas funções constitucionais, política de composição dos efetivos das Forças Armadas e reestruturação da Indústria brasileira de material de Defesa.

A END não estabeleceu hierarquia de prioridade entre os três eixos, contudo a reorganização da Indústria de Defesa, próximo tópico de análise, ganha destaque perante os demais na medida em que possui aliados fora do campo de atuação da Defesa, como centros de pesquisa e indústrias diversas, o que aumenta suas chances de execução. Por outro lado, os outros eixos são intrinsecamente ligados somente a Defesa. Além disso, o eixo em destaque, ao fornecer tecnologias avançadas, impacta tanto na composição 
do efetivo das Forças Armadas, ao permitir contingente menor e exigir pessoal mais especializado, quanto na ampliação das funcionalidades constitucionais da Marinha, Exército e Aeronáutica, o que permite acomodar outros interesses do cenário político nacional.

$\mathrm{Na}$ disciplina de relações internacionais em estudos de securitização atuais, teóricos da Escola de Copenhague também corroboram a importância do desenvolvimento da Indústria de Defesa (Buzan, Waever 1998). Estes acadêmicos incorporaram às ameaças militares outros temas como política, economia, meio-ambiente e sociedade, configurando a abordagem multissetorial das questões de Segurança: na área militar, o Estado é o principal objeto de referência, e as elites militares são os principais autores de iniciativas de securitização; no setor político, as ameaças têm por objetivo destruir ou abalar a soberania estatal; no setor econômico, a despeito da instabilidade natural causada pela busca do equilíbrio entre demanda e oferta, as ameaças seriam aquelas dirigidas a partes da economia que garantem a sobrevivência física do Estado, isto é, estendem-se às esferas política e militar; no setor societal, os objetos referentes são identidades coletivas que funcionam autonomamente em relação ao Estado, como nações e religiões; no setor ambiental o campo de estudo gira em torno do próprio meio-ambiente e da qualidade de vida já usufruída.

Ao analisar a relação entre os setores descritos, depreende-se que há dependência entre eles, de forma peculiar nos setores militar e econômico. A unidade de análise do setor econômico - a parte da economia que possibilita a continuação do Estado, como alimentos e indústria bélica em caso de guerra - está intimamente ligada ao setor militar. Caso a Indústria de Defesa seja anulada, um país fica sujeito a intenções alheias, em face da disparidade de poder entre os contendores.

Por sua vez, a Inteligência, para atingir e manter o estado de Segurança desejável, além de contribuir para tornar o processo decisório governamental mais racional e realista, atua também especificamente em relação à Defesa. O SI, entre outras funções, participa do planejamento da capacidade militar como desenvolvimento e aquisição de sistema de armas, a partir da análise de modernização de forças armadas de outros países; fornece aos comandantes militares avaliações e estimativas que os ajudam a entender o ambiente operacional; e, informa situação de outros atores que possam vir a apresentar potenciais ameaças ao Estado, sempre de forma antecipada (Estados Unidos 2013; Brasil 2005). No Brasil esta estrutura está representada, dentro do Sisbin, pelos centros de Inteligência dos comandos militares e Abin. ${ }^{1}$

Em suma, a Inteligência de Defesa se preocupa com a capacidade atual e a previsão de capacidade futura de potenciais inimigos (Herman 1996). 
É importante salientar que a existência de um órgão de Inteligência se faz necessário desde os tempos de paz, o que permite o pronto atendimento das forças armadas antes de surgir hostilidades.

Entretanto, o SI tende a apresentar o viés de sobrevalorizar o poder do inimigo, ou seja, lista mais suas forças do que fraquezas. O exemplo clássico se deu na guerra fria, em que analistas militares de Inteligência da Organização do Tratado do Atlântico Norte (Otan), pressionados pela guerra ideológica e no intuito de justificar seus orçamentos, preferiam errar para mais, em relação à ameaça soviética, do que serem surpreendidos (Herman 1996; Hobsbawn 2003). Para amenizar essa situação, é preciso que os analistas estejam abertos a todas as possibilidades e façam constante revisão das ideias.

\section{POLÍTICA PÚBLICA DE DESENVOLVIMENTO DA INDÚSTRIA DE DEFESA - NÍVEL MESO}

Desenvolvimento tecnológico tende a desequilibrar vantagens e capacidades entre países. Assim, dentro do eixo estruturante de desenvolvimento da Indústria de Defesa, faz-se necessário o estabelecimento de uma política pública, concebida em torno de interesses de Estado, o que evitaria a descontinuação de verbas para os programas militares. Como a Defesa é função primária do Estado e não pode ser delegada à iniciativa privada ou a outros órgãos da administração pública que não o Ministério da Defesa, este precisa transmitir a ideia para a sociedade que a Defesa Nacional é um bem público útil e necessário.

Como tal, em seu aspecto econômico a Defesa do país é um bem não rival - o consumo de uma unidade do serviço não reduz a quantidade disponível para outros consumidores - e não exclusivo - não se pode excluir uma pessoa do consumo daquele serviço. Assim, a Defesa é utilizada por todos, disponibilizada de forma igualitária e compulsória para toda a sociedade.

Além disso, o governo possui as funções econômicas alocativa (escolha de qual política será realizada), estabilizadora (aplicação de políticas públicas a fim de promover o emprego, o desenvolvimento e a estabilidade, diante da incapacidade do mercado em assegurar o atingimento de tais objetivos) e distributiva (redistribuição de rendas realizada por meio de transferências dos impostos e de subsídios governamentais). A política pública de desenvolvimento da Indústria de Defesa se relaciona de forma imediata com as duas primeiras funções, na medida em que precisa, quanto à função alocativa, estar alinhada com objetivos maiores do Estado, bem como assegurar inter-relação com outros planejamentos setoriais. Por exemplo, o programa de fortalecimento da Indústria de Defesa poderia utilizar 
projetos do programa Inova Empresa em áreas de aplicação indireta para a Defesa, a fim de desenvolver produtos de uso dual, como Inova Energia no segmento veículos híbridos e eficiência energética veicular. E, quanto à função estabilizadora, por meio do revigoramento da Indústria de Defesa, o governo criaria empregos e aumentaria exportações. Cumpre destacar também que o objetivo de desenvolver a Indústria nacional de Defesa vem ao encontro da ambição da maioria dos economistas, os quais almejam aumentar investimentos e inovações como forma de desenvolver a economia.

Segundo Furtado (1959), para superar a condição do Brasil de país subdesenvolvido, era necessário o fortalecimento do mercado interno, o desenvolvimento da indústria e a formação de capital intelectual para criação e difusão de progresso técnico. Ainda de acordo com o mesmo autor, esta revolução tecnológica não resultaria de forças espontâneas, e sim de uma intervenção consciente. Essa orientação parece válida ainda nos dias atuais para a Indústria de Defesa. Assim, levando em consideração o atual estágio de desenvolvimento da ciência no país e diante da necessidade de alguma tecnologia despertada para utilização interna ou por avanço de outras potências, o setor de Defesa possui três opções para satisfazer essa demanda: compra, parceria e desenvolvimento próprio² (ver Quadro 1).

$$
\begin{gathered}
\text { QUADRO } 1 \text { - Vantagens e desvantagens nas opções } \\
\text { de obtenção de tecnologia }
\end{gathered}
$$

\begin{tabular}{|l|l|l|}
\hline \multicolumn{1}{|c|}{$\begin{array}{c}\text { Opções para adquirir } \\
\text { tecnologia }\end{array}$} & \multicolumn{1}{|c|}{ Vantagens } & \multicolumn{1}{c|}{ Desvantagens } \\
\hline Compra de outra nação & $\begin{array}{l}\text { - Acesso imediato } \\
\text { - Custo conhecido } \\
\text { - Tecnologia já testada }\end{array}$ & $\begin{array}{l}\text { - Possível restrição } \\
\text { de acesso à "melhor" } \\
\text { tecnologia } \\
\text { - Manutenção da } \\
\text { dependência tecnológica }\end{array}$ \\
\hline $\begin{array}{l}\text { Parceria com outras nações } \\
\text { (codesenvolvimento ou } \\
\text { compra com transferência } \\
\text { de tecnologia) }\end{array}$ & $\begin{array}{l}\text { - Fortalece diplomacia } \\
\text { - Custo compartilhado } \\
\text { - Uso em dispositivos civis } \\
\text { e militares }\end{array}$ & $\begin{array}{l}\text { - Risco do parceiro } \\
\text { (desistência, falência, } \\
\text { mudança de prioridade, etc.) }\end{array}$ \\
\hline $\begin{array}{l}\text { Desenvolvimento próprio - } \\
\text { indústria nacional }\end{array}$ & $\begin{array}{l}\text { - Propriedade da tecnologia } \\
\text { - Exportação } \\
\text { - Uso em dispositivos civis } \\
\text { e militares }\end{array}$ & $\begin{array}{l}\text { - Possível demora no } \\
\text { desenvolvimento } \\
\text { - Custo total desconhecido }\end{array}$ \\
\hline
\end{tabular}

Fonte: Elaborado pelo autor.

Em qualquer opção escolhida, sempre que possível, é necessária sinergia com outros setores de segurança do país, a exemplo de polícias 
federais, militares, civis, corpo de bombeiros, guardas municipais e órgãos de Inteligência. Esta sinergia poderia se realizar na especificação técnica do bem e no aumento do volume de compras. Outras boas práticas no processo de aquisição de bens e tecnologias, em especial considerando desenvolvimento próprio via indústria nacional ou parceria com outras nações, são evidenciadas na Figura 2 (Reino Unido 2012).

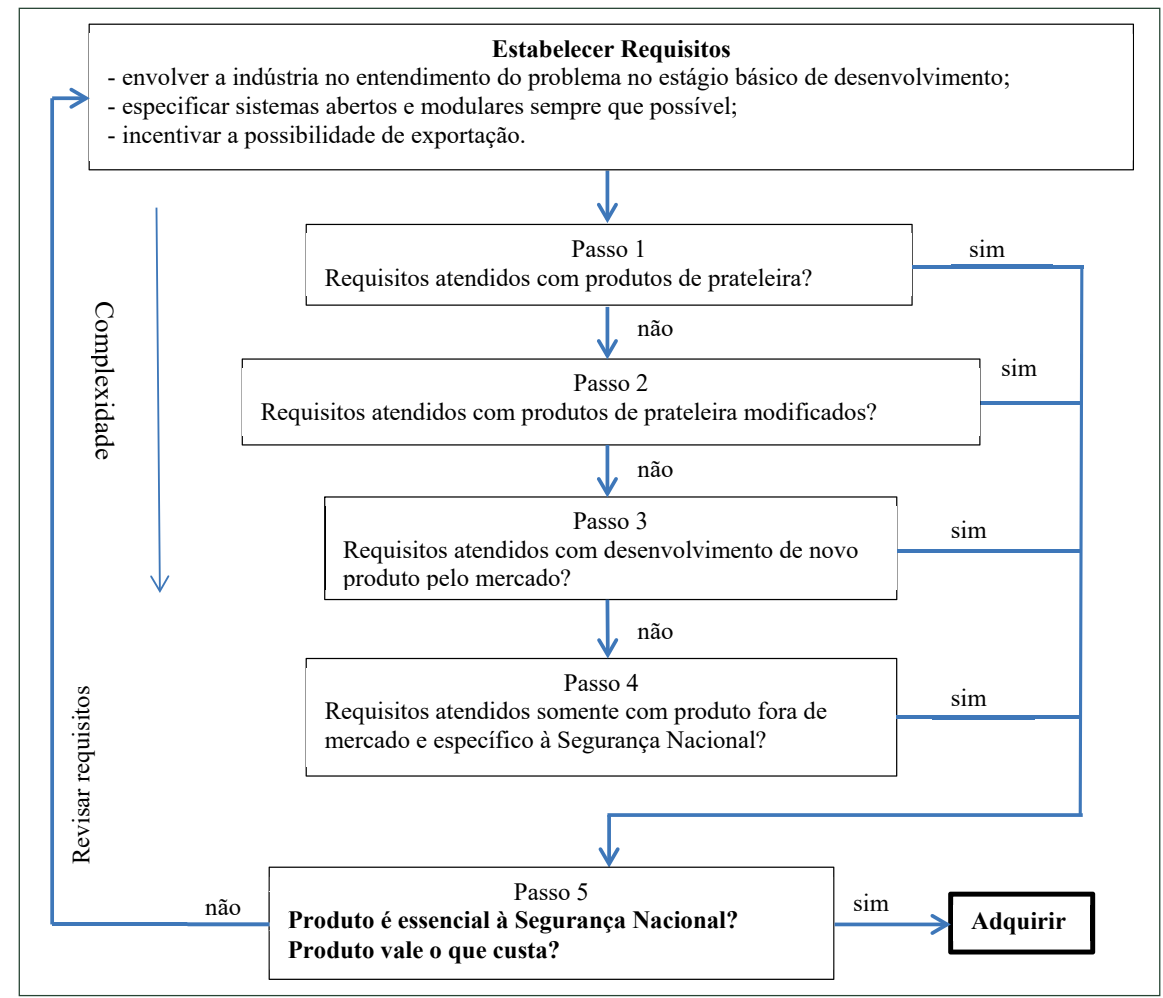

Figura 2 - Abordagem para aquisição de nova tecnologia Fonte: Adaptado de Reino Unido (2012).

No Brasil, a operacionalização do desenvolvimento da Indústria de Defesa ganhou destaque nos setores estratégicos: espacial (Aeronáutica), cibernético (Exército) e nuclear (Marinha) (Brasil 2008). Nos três setores se destaca o desenvolvimento de tecnologias e produtos de uso dual, civil e militar, pois potencializa os benefícios gerados. Também fortalece esta ideia o fato do país não vislumbrar guerras no médio e longo prazo, o que proporciona 
tempo para maturar tecnologias complexas, como geralmente são as duais. Além disso, a tecnologia de uso dual é mais provável de ser censurada, o que dificulta sua aquisição por compra ou parceria com outras nações. Por isso, o próximo tópico a ser analisado são os bens e tecnologias de uso dual, os quais impulsionam tanto a força econômica como militar de um país.

No processo de desenvolvimento de tecnologia, a Inteligência colabora com a política pública de desenvolvimento da Indústria de Defesa de três formas: agressiva, defensiva e consultiva. As alternativas não são mutuamente excludentes e sua efetivação depende de decisões da cúpula estatal.

$\mathrm{Na}$ forma agressiva, a Inteligência se aproxima do feitio cinematográfico hollywoodiano em que os espiões "roubam" segredos alheios. Talvez o exemplo clássico deste tipo de atuação seja o caso da primeira bomba atômica soviética. Após a Segunda Guerra Mundial, a União Soviética se viu em apuros diante do poder destruidor dessa nova bomba, pertencente a uma nação amiga em tempos da última guerra, porém ameaçadora em seguida. No fim da década de 1940, segundo cientistas e a agência de Inteligência americana, os russos completariam sua primeira bomba atômica em aproximadamente 10 anos. Contudo, em agosto de 1949, era detonada a bomba com os mesmos parâmetros da primeira explosão americana em 1945. Para americanos e ingleses, a resposta do enigma está na condenação de Klaus Fuchs, pelo sistema jurídico inglês, por repassar segredos da fissão nuclear aos russos. Registra-se que esta atividade sempre foi negada pela então União Soviética.

Em segundo lugar, na forma defensiva, a Inteligência atua em seu sentido oposto, isto é, a Contrainteligência procura identificar, avaliar, neutralizar e explorar as atividades de Inteligência dos adversários (Cleave 2007). Especificamente quanto aos segredos da Indústria de Defesa, a Inteligência protege o conhecimento, seja negando seu acesso, ou iludindo as ações inimigas (Herman 1996). No Brasil, a Abin possui o Programa Nacional de Proteção ao Conhecimento Sensível (PNPC) cuja finalidade é promover a proteção e a salvaguarda de conhecimentos que estejam relacionados aos interesses e à Segurança do Estado e da sociedade. Por último, a Inteligência colabora na escolha de tecnologias a serem desenvolvidas. Em seu caráter prospectivo, a Inteligência não trata apenas de ameaças, mas também de oportunidades. Ao explorar as assimetrias de informações, a Inteligência analisa as capacidades de outras nações e subsidia o decisor sobre qual tecnologia trará maior benefício ao país em determinado momento. Afinal, a utilidade do conhecimento forja sua própria prioridade.

Um erro comum na análise prospectiva é falhar no diagnóstico pelo fato do oponente poder realizar uma ação improvável por ignorância ou falta de 
discernimento; ou dos analistas pensarem que o oponente age da mesma forma que eles e não possuem um pensamento próprio. Por exemplo, no primeiro caso, a despeito da notável inferioridade militar dos árabes, estes atacaram Israel em 1973 e o fato não foi alertado pela Inteligência israelita por considerar o ataque improvável; no segundo caso, ocidentais tendem a analisar orientais (e vice-versa), sem se preocupar com viés cultural que cada povo possui (Hedley 2005).

\section{BENS E TECNOLOGIAS DE USO DUAL - NÍVEL MICRO}

Limitar a pesquisa de novos conhecimentos traz um paradoxo, pois estimula a curiosidade sobre o tema proibido (Demo 2013). Esta curiosidade do ser humano guia, em sua maior parte, o desenvolvimento da ciência para se alcançar vantagem comercial ou militar (Shattuck 1996). Verifica-se assim, ao longo da história, que há transbordo de tecnologias civis para militares e vice-versa. De modo mais específico à Indústria de Defesa, empresas civis participam da cadeia produtiva de produtos militares, ao passo que empresas dedicadas ao mercado militar atuam como integradoras de sistemas.

No caso brasileiro, nas políticas de Estado para Defesa, já estão previstos, entre outras ações, fomento a pesquisa e desenvolvimento de bens e tecnologias duais para reduzir dependência estrangeira e superar eventuais restrições de acesso. Contudo, os projetos nesta linha de ação não são prioritários dentro da agenda das forças armadas. Para ilustrar, citam-se alguns exemplos de bens de uso dual: acelerômetros incluídos em aparelhos celulares e que permitem identificar seu movimento ou rotação, para determinar a melhor orientação da tela, se vertical ou horizontal, e também podem ser usados em sistemas de direcionamento de mísseis; tecnologias de uso nuclear que são usadas na medicina e para propulsão de submarinos; veículos aéreos não tripulados (VANT) que são usados para mapeamento de áreas de risco e prevenção de inundações, além de uso para espionagem de tropas inimigas.

O desenvolvimento de bens e tecnologias de uso dual traz em si a complementaridade dos mercados civil e militar, já que o primeiro é mais dinâmico e competitivo, compensando a demanda irregular e restrições políticas do segundo. Por outro lado, o mercado militar, embasado em programas sólidos de conquistas de determinadas tecnologias garante recursos humanos e financeiros, nem sempre à disposição de agentes do mercado civil devido ao longo prazo de retorno. Além disso, de posse de tecnologia de ponta almejada por outros países, é possível impedir ou controlar seu desenvolvimento, garantindo vantagens comerciais em produtos civis, e, 
do lado militar, evitando o comprometimento operacional de suas próprias forças armadas.

A consequência primária de desenvolver e permitir ou restringir acesso a bens e tecnologias de uso dual é controlar o hiato tecnológico entre as nações. Surge então o dilema de vender (com ou sem transferência) tecnologia e lucrar, porém perdendo as vantagens comerciais e militares; ou manter as vantagens e não obter rendimentos de transação financeira (Longo, Moreira 2009). Aparentemente parece haver a solução de comercializar a penúltima inovação, de forma a obter lucro mesmo que seja menor e, ainda assim, manter vantagens militar e comercial da última inovação.

Pelo contexto militar, a interdependência de tecnologias civis e militares leva a preocupações sobre a salvaguarda de ativos e informações estratégicas, necessidade de acompanhar o desenvolvimento de pesquisas realizadas em outros países e controle do uso de tais tecnologias. Nas três linhas de ação, a Inteligência atua de forma decisiva.

No primeiro caso a Contrainteligência envida esforços para evitar ameaças, tais como espionagem, sabotagem e interferência externa. No segundo caso, como já dito anteriormente, a Inteligência observa o desenvolvimento de capacidades de potenciais adversários, e este acompanhamento é mais minucioso aqui, pois esta capacidade é influenciada pela aquisição ou detenção de bens e tecnologias duais devido a sua utilidade no desenvolvimento de novas armas.

Quanto à fiscalização no uso de bens e tecnologias duais é necessário antes fazer uma explicação sobre bens duais e sensíveis. Dentro do grupo de tecnologias de uso dual, a probabilidade de embargo internacional é maior nas tecnologias sensíveis, as quais podem ser usadas em armas de destruição em massa (ADM) e seus vetores. ADM é um dispositivo capaz de promover danos intencionais em grande escala, a exemplo de armas nucleares, químicas e biológicas; por sua vez, vetores são mísseis e veículos aéreos não tripulados que podem ser utilizados para lançamentos de ADMs (Barreto 2013). Já a legislação brasileira, por meio da Lei n. 9.112/95, considera bens sensíveis os bens de uso duplo e os bens de uso na área nuclear, química e biológica. Há no Brasil a Comissão Interministerial de Controle de Exportação de Bens Sensíveis (Cibes), formada, entre outros membros, pelos Ministérios da Ciência, Tecnologia e Inovação (MCTI) e Defesa, tendo a Abin como órgão assessor. Esta comissão é atenta à transferência clandestina de bens sensíveis, a qual acontece principalmente por meio de triangulações de empresas de diversos países, com desvio de mercadorias em portos intermediários, o que ocasiona cooperação com SIs estrangeiros.

Como exemplo de bens sensíveis de uso dual que necessitam de controle cita-se o caso dos subprodutos da mamoneira, cuja torta de mamona, 
rejeito da extração do óleo das sementes utilizada para produzir biodiesel, pode-se isolar a ricina, toxina com elevado poder de toxicidade. O MCTI e a Abin realizam o Programa Nacional de Integração Estado-Empresa na Área de Bens Sensíveis (Pronabens) com o foco de orientar empresas, indústrias e instituições de ensino e pesquisa sobre os controles governamentais para a transferência de tecnologias sensíveis e de uso dual.

A cooperação entre SIs tende a se intensificar a partir da percepção de ameaças comuns, além da congruência de interesses. Por outro lado, para concretizar cooperação eficiente, é necessário que todos os SIs envolvidos na cooperação saibam conduzir suas diferenças: de condução da política externa; de poder entre os parceiros; no tratamento de direitos humanos - apoiar quem não respeita esses direitos X proteger cidadãos; e, nas questões legais internas - aprovações e respeito a leis (Lefebvre, 2003). Outra preocupação diz respeito ao uso da informação passada a terceiros sem autorização de quem a originou.

\section{CASOS CONCRETOS DE RESTRIÇÃO E ACESSO A BENS E TECNOLOGIAS DE USO DUAL - NÍVEL NANO}

Como dito anteriormente, visando contornar cerceamento tecnológico, os países procuram acessar bens e tecnologias de uso dual por meio de desenvolvimento próprio, parceria com outra nação, ou compra. Em todas as modalidades há inúmeros exemplos de restrição e permissão de acesso a estas tecnologias.

Este cerceamento foi institucionalizado em 1949 por meio da criação, pelos Estados Unidos e seus aliados, do Coordinating Commitee For Multilateral Export Control (CoCom), primeira organização direcionada a controlar as exportações de materiais estratégicos e tecnologia para o mundo comunista (Longo, Moreira 2009). Após o fim da guerra fria, este acordo foi substituído pelo The Wassenaar Arrangement on Export Controls for Conventional Arms and Dual-Use Goods and Technologies. Inúmeros outros tratados e convenções foram criados com o mesmo propósito e, especificamente em relação ao Brasil, o país se compromete com os seguintes mecanismos internacionais: tratados na área nuclear (Tratado de Tlatelolco e Tratado de Não Proliferação de Armas Nucleares); Grupo de Supridores Nucleares; Regime de Controle de Tecnologia de Mísseis; Convenção para Proibição de Armas Químicas; Convenção para Proibição de Armas Biológicas; e Resoluções do Conselho de Segurança da Organização das Nações Unidas (Barreto 2013).

Como exemplos de casos de restrição de acesso a bens e tecnologias de uso dual citam-se as vendas de aviões Tucanos para a Venezuela em 2005 e 
o desenvolvimento de foguetes brasileiro-ucranianos em 2009. No primeiro exemplo, a Embraer pretendia vender aeronaves Super Tucano para a Venezuela, porém foi impedida pelos Estados Unidos, país sede de empresas que fornecem componentes para o avião. A Venezuela adquiriu aviões da Rússia para fugir do embargo estadunidense. No segundo exemplo, de acordo com o site Wikileaks, autoridades do governo norte-americano teriam pressionado o governo ucraniano a não prosseguir com o desenvolvimento de implantação da plataforma de lançamento dos foguetes Cyclone 4, no centro de lançamentos de Alcântara.

Por outro lado, apresentam-se como exemplos de casos de permissão de acesso a bens e tecnologias de uso dual os casos da construção da usina nuclear Angra II e compra dos aviões caças Saab Gripen da Suécia para a Força Aérea Brasileira. Em relação à usina de Angra dos Reis/RJ, foi assinado em 1975 um acordo de construção e transferência de tecnologia com a Alemanha, o que propiciou ao país domínio sobre praticamente todas as etapas de fabricação do combustível nuclear. Estes conhecimentos estão sendo úteis no desenvolvimento do submarino com propulsão nuclear pela Marinha do Brasil. Quanto aos aviões de combate, o recente anúncio brasileiro pela escolha dos caças suecos iniciou o processo de aproximação entre o MCTI com o governo e empresa suecos para formatar o modelo de transferência de tecnologia associada aos aviões, conforme consta no acordo de compra.

A partir dos exemplos citados, verifica-se a necessidade, entre outras, de um aparato de Segurança que propicie condições ideais para o controle do uso e o acesso a tecnologias e bens duais. O SI atua como mais um elemento deste aparato, ao lado das forças armadas e das forças policiais em conjunto com o sistema jurídico.

O SI destaca-se das demais entidades de Segurança devido ao seu modo de agir em casos de condutas suspeitas de vazamentos de informações estratégicas, ameaças de sabotagem, terrorismo, tentativas de interferência externa e espionagem. A principal diferença entre a abordagem da Inteligência e das forças tradicionais de manutenção da ordem reside no fato de que a primeira atua com mais ênfase na prevenção de futuros eventos danosos. Por exemplo, enquanto indivíduos ou grupos planejam uma determinada ação de espionagem e eventualmente ainda não tenham cometido algum crime, como planejar ações estando fora do país alvo, eles não podem ser detidos, porém podem ser vigiados pela Inteligência (Jackson 2009). Assim, calculando os riscos da continuação da operação de espionagem e respeitando a legislação vigente pode ser mais interessante para o SI acompanhar estas pessoas e verificar quais são os elos, do que denunciá-las imediatamente, como normalmente fariam as forças de Segurança tradicionais. 
Contudo, sobre a atividade de Inteligência recaem preocupações acerca do efeito de seus atos na privacidade das pessoas e respeito aos direitos civis. Para anular esta inquietação torna-se necessário definir a correta relação entre as forças de aplicação da lei e o SI, bem como controle externo da atividade da Inteligência - comumente realizado pelo parlamento (Gonçalves 2008). No Brasil, foi aprovado em meados de 2014 o regimento interno da Comissão Mista de Controle das Atividades de Inteligência (CCAI) do Congresso Nacional, que lhe permite funcionamento e consequente fiscalização da atividade de Inteligência no país.

\section{CONCLUSÕES}

É importante ressaltar que não se avaliza a corrida armamentista, em que todos ficam mais armados e menos seguros. Na verdade, todos os países tendem a ficar mais mal armados, visto que há variação do gasto em Defesa ao longo do tempo, mesmo em países centrais, e com maior ênfase, em países periféricos. Além disso, o caráter errático, mesmo considerando investimentos financeiros maciços, imanente ao desenvolvimento de inovações também corrobora as oscilações na capacidade militar de um país.

Pelo contrário, defende-se o desenvolvimento da indústria que leve a criação de produtos duais, de aplicação civil, para melhora da qualidade de vida da população, e aplicação militar, para manter estáveis os limites fronteiriços, projetar poder no exterior para conciliar interesses, persuadir intromissões externas, e contribuir para Segurança jurídica em quaisquer atos no território nacional. Isto sempre na busca da mudança de um paradigma competitivo de Segurança Nacional para outro cooperativo de Segurança Global (McCgwire 2002). Destaca-se também o dever de observar todos os compromissos internacionais já assumidos pelo Brasil, bem como a ética e o perfil pacifista do país, quando da escolha das tecnologias a serem desenvolvidas e da forma de atuação do SI.

O Brasil se depara com o dilema entre optar pelo perfil de empresa e mercado simplesmente exportador ou se consolidar como potência regional (Prado Junior 2011; Becker 2006), rumo a ser potência global. Em se tratando da segunda e melhor opção, e fundamentado nas observações de cada tópico de análise estudado anteriormente, apresenta-se a proposição seguinte ilustrada na Figura 3:

Proposição - A execução da política pública de desenvolvimento da Indústria de Defesa conduz tanto ao fortalecimento da economia, quanto ao provimento das Forças Armadas; e ambos fortalecem a Segurança do país. A produção de bens e tecnologias de uso dual atua como variá- 
vel moderadora, influenciando de maneira positiva a economia (uso civil e militar), e tornando as Forças Armadas melhor equipadas (uso militar). A Segurança, uma vez atingida e mantida, fornece bases para realização dos interesses nacionais, além de retroalimentar o desenvolvimento da Indústria de Defesa. Distingue-se que todo o processo é amparado pela Inteligência, por meio da incorporação de suas contribuições.

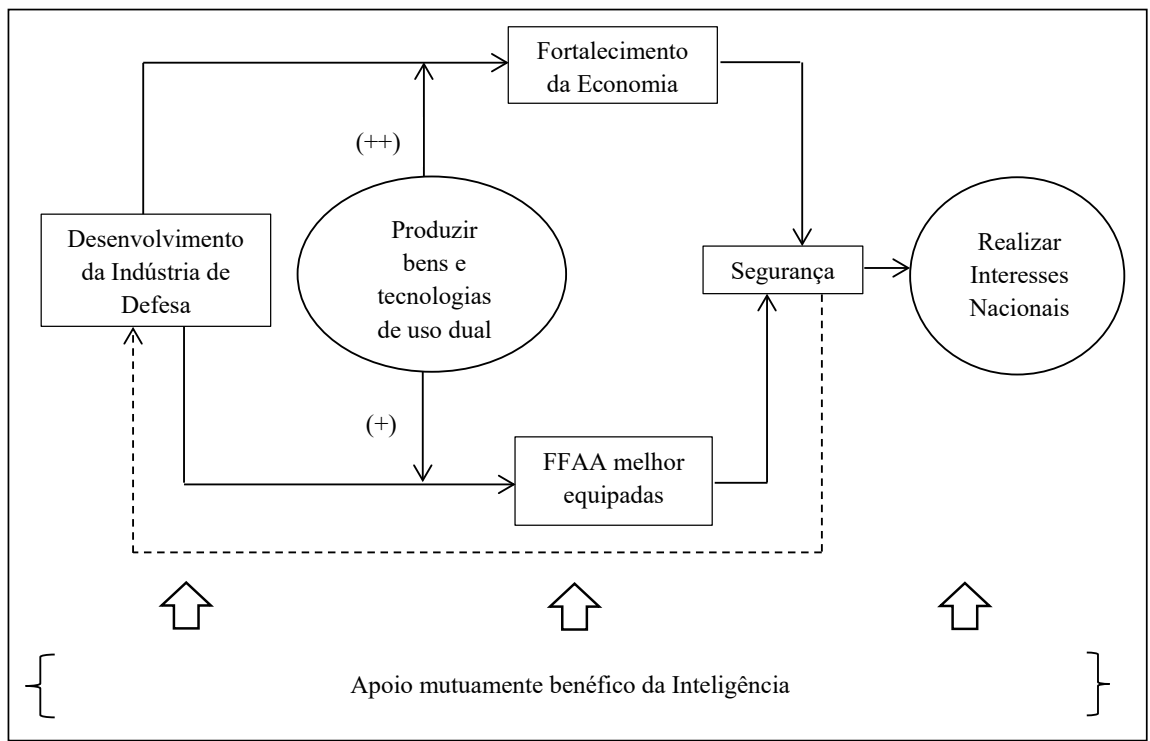

Figura 3 - Esquema relacional entre Indústria de Defesa, Inteligência, Segurança e interesses nacionais

Fonte: Elaborado pelo autor.

Cumpre salientar que a Inteligência tem caminho maior a percorrer do que o desenvolvimento da Indústria de Defesa, uma vez que o Brasil carece ainda da definição da Política Nacional de Inteligência (PNI) e consequentes Planos de Inteligência (Pinheiro 2012). A PNI deveria também, a exemplo da PND, ser um documento sem classificação sigilosa por três motivos: permitir maior controle e confiança por parte dos cidadãos, legitimar os atores desta atividade perante a sociedade e diminuir eventuais desconfianças por parte de países parceiros.

Isto posto, apresenta-se o Quadro 2 abaixo com a categorização das ideias apresentadas, as quais contribuem para a realização de interesses nacionais a partir da interpretação da Defesa e da Inteligência. 
QUADRO 2 - Categorização de conceitos de Defesa e Inteligência em prol de interesses nacionais

\begin{tabular}{|c|c|c|c|}
\hline Nível & \multicolumn{3}{|c|}{ Tópico } \\
\hline \multirow[t]{4}{*}{ Meta } & \multicolumn{3}{|c|}{ Segurança Nacional } \\
\hline & Defesa & \multicolumn{2}{|c|}{ Inteligência } \\
\hline & \multirow{2}{*}{$\begin{array}{l}\text { Estado necessita Segurança } \\
\text { para realizar interesses nacio- } \\
\text { nais, isto é, ganhos sociais e } \\
\text { econômicos para a população }\end{array}$} & \multirow{2}{*}{$\begin{array}{l}\text { Obtenção, análise e dis- } \\
\text { seminação da informação } \\
\text { para auxiliar processo } \\
\text { decisório do Executivo, } \\
\text { além de salvaguarda de } \\
\text { informações }\end{array}$} & Atenção \\
\hline & & & $\begin{array}{l}\text { Diminuir incertezas } \\
\text { sem impor alternati- } \\
\text { va ao decisor }\end{array}$ \\
\hline \multirow[t]{4}{*}{ Macro } & \multicolumn{3}{|c|}{ Política e Estratégia de Defesa } \\
\hline & Defesa & \multicolumn{2}{|c|}{ Inteligência } \\
\hline & \multirow[b]{2}{*}{$\begin{array}{l}\text { Segurança, do ponto de vista } \\
\text { externo, necessita forças ar- } \\
\text { madas bem preparadas. Três } \\
\text { eixos estruturantes, sendo } \\
\text { principal a reorganização da } \\
\text { Indústria de Defesa }\end{array}$} & \multirow{2}{*}{$\begin{array}{l}\text { Participação no plane- } \\
\text { jamento da capacidade } \\
\text { militar }\end{array}$} & Atenção \\
\hline & & & $\begin{array}{l}\text { Não sobrevalorizar o } \\
\text { oponente, por meio } \\
\text { de questionamento } \\
\text { contínuo de concei- } \\
\text { tos e opiniões }\end{array}$ \\
\hline \multirow[t]{4}{*}{ Meso } & \multicolumn{3}{|c|}{ Política pública de desenvolvimento da Indústria de Defesa } \\
\hline & Defesa & \multicolumn{2}{|c|}{ Inteligência } \\
\hline & \multirow[b]{2}{*}{$\begin{array}{l}\text { Opções para adquirir tecnolo- } \\
\text { gia, em ordem de prioridade: } \\
\text { desenvolvimento próprio, } \\
\text { parceria com outros países e } \\
\text { compra. Procurar estabelecer } \\
\text { requisitos em comum acordo } \\
\text { com a indústria, sempre in- } \\
\text { dagar se o projeto é essencial } \\
\text { à Segurança Nacional e se } \\
\text { vale o que custa. Desenvolvi- } \\
\text { mento de tecnologias de uso } \\
\text { dual potencializa benefícios } \\
\text { gerados }\end{array}$} & \multirow[b]{2}{*}{$\begin{array}{l}\text { Atuação: agressiva - es- } \\
\text { pionagem de segredos } \\
\text { industriais; defensiva } \\
\text { - proteção de conheci- } \\
\text { mentos; consultiva - as- } \\
\text { sessoria na escolha do que } \\
\text { desenvolver }\end{array}$} & Atenção \\
\hline & & & $\begin{array}{l}\text { Antecipar ações } \\
\text { improváveis dos } \\
\text { adversários. Fazer } \\
\text { análise levando em } \\
\text { consideração viés } \\
\text { cultural }\end{array}$ \\
\hline
\end{tabular}




\begin{tabular}{|c|c|c|c|}
\hline Nível & \multicolumn{3}{|c|}{ Tópico } \\
\hline \multirow[t]{4}{*}{ Micro } & \multicolumn{3}{|c|}{ Acesso a bens e tecnologias de uso dual } \\
\hline & Defesa & \multicolumn{2}{|c|}{ Inteligência } \\
\hline & \multirow[b]{2}{*}{$\begin{array}{l}\text { Transbordo de tecnologias ci- } \\
\text { vis para militares e vice-ver- } \\
\text { sa. Complementaridade dos } \\
\text { mercados civis e militares } \\
\text { para bens e tecnologias duais. } \\
\text { Possibilidades de se manter } \\
\text { ou não vantagens militar e } \\
\text { comercial: vender a melhor } \\
\text { ou a penúltima tecnologia; } \\
\text { ou, ainda, restringir acesso } \\
\end{array}$} & \multirow[b]{2}{*}{$\begin{array}{l}\text { Proteção de ativos e in- } \\
\text { formações estratégicas, } \\
\text { acompanhamento de } \\
\text { pesquisas no exterior e } \\
\text { monitoramento do uso de } \\
\text { tecnologias duais e sen- } \\
\text { síveis }\end{array}$} & Atenção \\
\hline & & & $\begin{array}{l}\text { Cooperar com } \\
\text { outros SIs é mais } \\
\text { proveitoso se há } \\
\text { ameaças comuns e } \\
\text { mesmos interesses }\end{array}$ \\
\hline \multirow[t]{4}{*}{ Nano } & \multicolumn{3}{|c|}{ Casos concretos de acesso e restrição a bens e tecnologias de uso dual } \\
\hline & Defesa & \multicolumn{2}{|c|}{ Inteligência } \\
\hline & \multirow[b]{2}{*}{$\begin{array}{l}\text { Institucionalização do con- } \\
\text { trole de acesso a tecnologias } \\
\text { e bens duais por meio da } \\
\text { criação de comitês e tra- } \\
\text { tados internacionais. Ex.: } \\
\text { restrição - venda de aviões } \\
\text { tucanos para Venezuela e } \\
\text { desenvolvimento de foguetes } \\
\text { brasileiro-ucranianos; acesso } \\
\text { - construção da usina nuclear } \\
\text { Angra II e compra dos caças } \\
\text { Gripen da Suécia }\end{array}$} & \multirow{2}{*}{$\begin{array}{l}\text { Atuação com ênfase na } \\
\text { prevenção de atividades } \\
\text { suspeitas. Permite acom- } \\
\text { panhamento e não exige } \\
\text { denúncia imediata }\end{array}$} & Atenção \\
\hline & & & $\begin{array}{l}\text { Preocupar com } \\
\text { efeito da atividade } \\
\text { de Inteligência sobre } \\
\text { a privacidade das } \\
\text { pessoas e respeitar } \\
\text { os direitos civis. } \\
\text { Amenizar por meio } \\
\text { de controle externo } \\
\text { (Congresso Nacio- } \\
\text { nal) da atividade de } \\
\text { Inteligência }\end{array}$ \\
\hline
\end{tabular}

Fonte: Elaborado pelo autor.

Atualmente, o Estado, em busca de eficiência, procura se apresentar menos como burocrático e mais como informacional, isto é, os detentores do poder colocam o controle, o tratamento, os fluxos e a utilização da informação para exercício do poder (Braman 2006). Desse modo, sugere-se em futuro estudo acrescentar a diplomacia como terceiro pilar da gestão da Segurança Nacional e investigar a inter-relação entre os três setores - Defesa, Inteligência e Diplomacia - para a consecução dos interesses nacionais.

Outra linha de estudo possível seria pesquisar, de forma comparativa, qual o impacto da política de desenvolvimento da Indústria de Defesa para a Segurança Nacional em países com desafios e características semelhantes ao Brasil. $\mathrm{Ou}$, ainda, analisar de modo aprofundado casos de desenvolvimento ou compra com transferência de tecnologia de produtos de uso dual para verificar os impactos na Segurança Nacional do país. 


\section{REFERÊNCIAS}

Barreto, E. M. 2013. A proliferação de armas de destruição em massa e a atividade de Inteligência. Revista Brasileira de Inteligência, 8.

Becker, B. K., Egler, C. A. G. 2006. Brasil: Uma nova potencia regional na economiamundo. 5. ed. Rio de Janeiro: Bertrand Brasil.

Bimfort, M. T. 1958. A Definition of Intelligence. Studies in Intelligence, 4: 75-78.

Braman, S. 2006. Change of state: information, policy and power. Cambridge: The MIT Press.

Brasil. 1988. Constituição da República Federativa do Brasil. Brasília: Senado.

Brasil. 1999. Lei $\mathrm{N}^{\circ}$ 9.883, de 7 de dezembro de 1999. Institui o Sistema Brasileiro de Inteligência, cria a Agência Brasileira de Inteligência - ABIN, e dá outras providências. Diário Oficial da República Federativa do Brasil. Brasília, 8 de dezembro.

Brasil. Ministério da Defesa. 2005. Política de Defesa Nacional. Brasília, 30 de junho. Disponível em http://www.planalto.gov.br/ccivil_03/_Ato2004-2006/2005/ Decreto/D5484.htm.

Brasil. Ministério da Defesa. 2008. Estratégia Nacional de Defesa. 2. ed. Brasília.

Buzan, B., Waever, O. 1998. Security: a new framework for analysis. London: Lynne Rienner Publishers.

Cepik, M. 2002. Inteligência e Políticas Públicas: dinâmicas operacionais e condições de legitimação. Security and Defense Studies Review, 2 (2).

Cleave, M. V. 2007. Strategic Counterintelligence: What Is It and What Should We Do About It? Unclassified Studies in Intelligence, 51 (2).

Demo, P. 2013. Metodologia do Conhecimento Científico. São Paulo: Editora Atlas.

Deutsch, H. C. 1988. Commanding Generals and the Uses of Intelligence. Intelligence and National Security, 3: 194-260.

Diniz, M. A. D. 2002. Profissionalização da Atividade de Inteligência. Seminário Atividades de Inteligência no Brasil: contribuições para a Soberania e a Democracia. Câmara dos Deputados. Disponível em: http://www.senado.gov.br/comissoes/ CCAI/txtMarisa.htm. 
Eisenhardt, K. M. 1989. Building theories from case study research. Academy of Management Review, 14 (4): 532-550.

Estados Unidos. 2013. Joint Intelligence. Joint chiefs of staff.

Furtado, C. 1959. Formação Econômica do Brasil. São Paulo: Companhia das Letras.

Gonçalves, J. B. 2008. O controle da atividade de Inteligência em regimes democráticos: os casos de Brasil e Canadá. Tese (doutorado). Universidade de Brasília.

Hedley, J. H. 2005. Learning from Intelligence Failures. International Journal of Intelligence and CounterIntelligence, 3: 435-450.

Herman, M. 1996. Intelligence power in peace and war. Cambridge: Cambridge University Press.

Hobbes, T. 1985. Leviathan. Londres: Penguin Group.

Hobsbawm, E. 2003. A era dos extremos: o breve século XX 1914-1991. São Paulo: Companhia das Letras.

Jackson, B. A. 2009. Considering the creation of a domestic intelligence agency in the United States: lessons from the experiences of Australia, Canada, France, Germany, and the United Kingdom. RAND Corporation.

Lefebvre, S. 2003. The Difficulties and Dilemmas of International Intelligence Cooperation. International Journal of Intelligence and CounterIntelligence, 4: 527-542.

Longo, W. P. e, Moreira, W. de S. 2009. O acesso a "tecnologias sensíveis". Tensões Mundiais, 5 (9): 73-98.

Maquiavel, N. 1979. O Príncipe. São Paulo: Abril Cultural.

McCgwire, M. 2002. Shifting the paradigm. International Affairs, 78 (1): 1-28.

Moore, David T. 2007. Critical Thinking and Intelligence Analysis. National Defense Intelligence College. Washington.

Odom, W. E. 2008. Intelligence Analysis. Intelligence and National Security, 23 (3): 316-332.

ONU. 2015. Assembleia Geral das Nações Unidas. Transforming our World: the 2030 Agenda for Sustainable Development. 
Pinheiro, M. M. K. 2012. Estado informacional: implicações para as políticas de informação e de inteligência no limiar do século XXI. Varia História, 28 (47): 61-77.

Prado Junior, C. 2011. Formação do Brasil Contemporâneo. São Paulo: Companhia das Letras.

Proença Junior, D. 2009. Condicionantes e Requisitos para um Sistema de Inteligência Vantajoso para o Brasil. Nota Técnica de Inteligência CGEE GSI. Disponível em: http://geopr 1.planalto.gov.br/saei/images/publicacoes/ntsisinteligenciafinalpb.pdf. Acesso em: 06 jun. 2012. 1998. Política de Defesa no Brasil: uma análise crítica. Brasília: Ed. UnB.

Reino Unido. 2012. National Security Through Technology: Technology, Equipment, and Support for UK Defence and Security. Ministry of Defence.

Ribeiro, R. J. 2008. Sobre o conceito de interesse nacional. Revista Interesse Nacional, $2(1): 76-85$.

Shattuck, R. 1996. Forbidden Knowledge: from Prometeus to pornography. New York: St. Martin’s Press.

Silveira, R. M. 2004. Segurança e Defesa - a visão do Exército Brasileiro. In: Pinto, J. R. de Almeida, Rocha, A. J. Ramalho, Silva, R. D. P. da (Org.). Reflexões sobre defesa e segurança: uma estratégia para o Brasil. Brasília: Ministério da Defesa, Secretaria de Estudos e de Cooperação, v. 1.

Waltz, K. N. 1979. Theory of international politics. New York: McGraw Hill.

Williamson, O. 1975. Markets and Hierarchies. New York: The Free Press.

Williamson, O. 1985. The Economic Institutions of Capitalism. New York: The Free Press. 


\section{NOTAS}

1. Também no Brasil, no âmbito do Ministério da Defesa e das Forças Armadas foi instituído em 2002 o Sistema de Inteligência de Defesa (Sinde), composto somente pela Inteligência dos comandos militares e caracterizado por ser técnico-militar especializado, com atuação em Inteligência estratégica e operacional de Defesa.

2. Aqui, opta-se pelo critério de envolvimento ou não de outro país para aquisição de uma tecnologia. Este outro país deve ser detentor de relevantes conhecimentos na área a ser desenvolvida. 


\section{INTERAÇÕES ENTRE DEFESA E INTELIGÊNCIA: A CONTRIBUIÇÃO DESSES SETORES PARA A REALIZAÇÃO DE INTERESSES NACIONAIS}

\section{RESUMO}

O objetivo deste trabalho é demonstrar, com ênfase no Brasil, que para se desenvolver o país, é necessário ter Segurança Nacional por meio do fortalecimento da Defesa, ação sempre amparada pela Inteligência. São analisados qualitativamente cinco tópicos de atuação da Defesa e Inteligência, pertencentes a níveis de abrangência diferentes: segurança nacional, política e estratégia de defesa, política pública de desenvolvimento da indústria de defesa, bens e tecnologias de uso dual e casos concretos de acesso e restrição a estes bens e tecnologias. Os critérios técnicos de escolha dos tópicos foram as prioridades de Estado, aliados a parâmetros de maiores utilidade para a sociedade e probabilidade de realização. Os resultados apontam que o desenvolvimento da Indústria de Defesa, maximizado pela produção de bens e tecnologias duais e pelo apoio da Inteligência, desenvolve a economia e torna as Forças Armadas melhor equipadas. Processo que alimenta a Segurança, a qual por sua vez fornece bases para realização dos interesses nacionais.

Palavras-chave: Segurança Nacional; Indústria de Defesa; Inteligência; Interesse nacional.

\section{ABSTRACT}

This study aims to demonstrate, with emphasis on Brazil, that to develop the country it is necessary to have national security by strengthening the defense, action always supported Intelligence Services. Five topics of expertise on Defense, belonging to different coverage levels, are to be qualitatively analyzed: National Security and Defence Policy Strategy, Public Policy development of defense industry, Goods and dual-use technologies and access to concrete cases and restriction to these goods and technology. The technical criteria for selecting the topics were the state priorities, together to utility parameters for the society and the likelihood of their accomplishmet. The results show that the development of the defense industry, maximized by the production of dual-use goods and technologies, develop the economy and make the military better equipped, in a process that feeds back the security, which in turn provides basis for the accomplishment of national goals.

Keywords: National Security; Defense Industry; Intelligence; National Goals.

Recebido em: 04/02/2016. Aceito para publicação em: 09/06/2016. 